\title{
Celebrity entrepreneurship: communication effectiveness through perceived involvement
}

\section{Erik Hunter* and Per Davidsson}

Jönköping International Business School

P.O. Box 1026

SE-55111 Jonkoping, Sweden

and

Brisbane Graduate School of Business

Queensland University of Technology

2 George Street, Brisbane 4000, Australia

E-mail: erik.hunter@ihh.hj.se

E-mail: per.davidsson@qut.edu.au

*Corresponding author

\begin{abstract}
Increasingly, celebrities appear not only as endorsers for products but are apparently involved in entrepreneurial roles in the ventures that market the products they promote. We call this phenomenon Celebrity Entrepreneurship. We hypothesise that celebrity entrepreneurs are more effective communicators than typical celebrity endorsers. Further, we hypothesize that this is because celebrity entrepreneurship leads to higher perceptions of Involvement - an endorser quality hitherto neglected in the marketing communication literature - which in turn affects traditional outcome variables such as Aad and Abr. Two experiments confirm that a) involvement can successfully be operationalised as distinct from variables previously shown to influence communicator effectiveness, b) involvement has a positive effect on Aad and Abr over and above the traditional predictors, and c) celebrity entrepreneurship in experimental manipulations leads to increased perceived involvement.
\end{abstract}

Keywords: celebrity endorser; celebrity entrepreneurship; source involvement; source model.

Reference to this paper should be made as follows: Hunter, E. and Davidsson, P. (2007) 'Celebrity entrepreneurship: communication effectiveness through perceived involvement', Int. J. Entrepreneurship and Small Business, Vol. 4, No. 5, pp.505-527.

Biographical notes: Erik Hunter teaches Marketing Management at the Jönköping International Business School and Entrepreneur \& Business Planning at the Stockholm School of Economics in Riga. His research is tied to the Entrepreneurship Research Lab (ERL) of Jönköping and is focused on all things related to Celebrity Entrepreneurship. In particular, using experiments to determine how Celebrity Capital as a unique and exploitable resource is used and leveraged in an entrepreneurial setting. Hunter received his Bachelor of Science at Florida State University and MBA from the Purdue University. Currently, Hunter is a PhD candidate at the Jönköping International Business School. 
Per Davidsson is Professor in Entrepreneurship and Director of Research at the Brisbane Graduate School of Business and has a second affiliation with the Jönköping International Business School. He has published over 100 works on various entrepreneurship-related topics, including his recent book 'Researching Entrepreneurship' (Springer, 2004), which is the only major text specifically designed to guide doctoral students and other new entrants to this field of research. He serves on the editorial boards for the leading journals in the field, and frequently appears as keynote speaker at conferences. Professor Davidsson has led research programmes such as Program on Entrepreneurship and Growth in SMEs (PEG) and the Entrepreneurship Research Laboratory $(E R L)$, and is currently building up the Comprehensive Australian Study of Entrepreneurial Emergence (CAUSEE).

\section{Introduction}

We believe this represents the first empirical research study into an important and new phenomenon: Celebrity Entrepreneurship. If media coverage and reports are to be believed, more and more celebrities are starting firms and other ventures (see e.g., Dow, 2005; Miller, 2004; Stanley, 2004). While we consider celebrity entrepreneurship a new scholarly phenomenon it does share many similarities with celebrity endorsement; a phenomenon that for the last 100 years has been extensively employed by advertisers (Jacobson et al., 2001) and an area of interest for researchers spanning 60 years (Kaikati, 1987).

Much of the existing celebrity endorsement literature seeks to identify the factors and conditions that lead to celebrity endorser effectiveness (Erdogan, 1999). ${ }^{1}$ Three characteristics are particularly recurrent in the literature: the endorser's trustworthiness, attractiveness and expertise. It is conceivable that being (one of) the entrepreneur(s) behind the project rather than 'just' being an endorser increases communicator effectiveness via increased perceptions of trustworthiness, attractiveness and expertise. However, we argue that celebrity entrepreneurship status mainly works through increased perceptions of involvement - a factor hitherto overlooked in the marketing communication literature. Consequently, in this research we aim to demonstrate that:

- involvement is a communicator characteristic that is distinct from the traditional characteristics trustworthiness, attractiveness and expertise

- the degree of perceived involvement contributes to communicator effectiveness over and above what can be explained by the other three communicator characteristics

- under otherwise identical conditions a celebrity entrepreneur is ascribed higher involvement than is a traditional celebrity endorser.

It is in the interest of several stakeholders to develop knowledge about if and how celebrity entrepreneurship works. First, new venture founders and marketers have an interest in knowing if and when it is worth considering involving a celebrity more deeply than as an endorser. Second, celebrities themselves have an interest in learning how to best capitalise on their 'celebrity capital'. Third, consumers and those who protect their interests have an interest in understanding celebrity entrepreneurship as a factor that potentially affects consumers' product preferences and choices. Finally, for researchers in 
entrepreneurship and marketing communication this study contributes new insights into phenomena within their respective domains. To the marketing communication literature we offer the identification and proven effect of an additional Source Model variable: Involvement. To entrepreneurship we contribute the opening up of research into a new, entrepreneurial phenomenon. In this context we regard 'celebrity capital' as a previously neglected, yet relevant resource dimension to consider.

\section{Theoretical background}

Celebrities are used in endorsement for a range of reasons. There are times when celebrities are called upon to forge a brand's image. According to Dickenson (1996), celebrities are known to 'instantly' impart personality and appeal onto unknown products, and in turn create a recognised entity. For brands that lack appeal, or are simply in need of a 'personality injection', celebrities have been used to aid in re-branding and re-positioning (Jacobson et al., 2001). As several authors have pointed out, consumers have an insatiable desire to learn more about the private lives of celebrities (Gamson, 1994; Ponce de Leon, 2002). This makes celebrities good 'attention getters' (Kaikati, 1987) that are particularly effective at generating PR for products (Chapman and Leask, 2001; Larkin, 2002; Pringle and Binet, 2005) and high consumer recall rates when exposed to celebrity ads (Kamen et al., 1975; O'Mahony and Meenaghan, 1998).

Given findings from academic and company reports, Erdogan (1999) argues that celebrity endorsers are more effective than non celebrity endorsers in generating 'all' desirable outcomes, including but not limited to attitudes towards advertising and endorsed brand, intention to purchase, and actual sales. However, claiming celebrity endorsers are more effective, in general, is very different from claiming they are more effective in specific cases. Numerous examples, such as Britney Spears getting caught on camera drinking Coca Cola while acting as the leading spokesperson for Pepsi Cola; John Wayne's seeming dream marriage with the product Datril which ended in divorce due to a lackluster response from consumers; and the embarrassment Cybil Shepherd caused the US Beef Industry when acting as their leading spokesperson admitted to not eating beef, have taught us that a high profile celebrity combined with a product is not a sure strategy for success.

\subsection{Source trustworthiness, expertise, and attractiveness: the source model}

Over the years, researchers in the fields of marketing, communications and social psychology have tried to identify factors related to the endorser that are central to understanding and improving their effectiveness. The theoretical basis for assuming that an advertisement's effectiveness increases relative to the trustworthiness, expertise, and attractiveness of the communicator stems from two research streams: source credibility (comprised of source trustworthiness and source expertise) and source attractiveness (also referred to collectively as the source models). From their study in 1953, Hovland et al. established the source credibility model and defined expertise as "the extent to which a communicator is perceived to be a source of valid assertions" (p.21) and trustworthiness as "the degree of confidence in the communicator's intent to communicate the assertions he considers most valid" (p.21). 
Source Attractiveness does not refer to physical attractiveness per se - it is related to three more general concepts: similarity, familiarity, and liking. The model holds that the effectiveness of a message depends on the source's familiarity, likeability, similarity, and attractiveness to the respondent. Familiarity is considered knowledge of the source through exposure, whereas likeability is affection for the source as a result of the source's physical appearance and behaviour; and similarity is the supposed resemblance between the source and the receiver of the message (McGuire, 1985).

According to the source models, endorsers are effective when they are seen by consumers as trustworthy (Friedman and Friedman, 1976; Miller and Basehart, 1969), experts (Crano, 1970; Crisi and Kassinove, 1973; Woodside and Davenport, 1974), and attractive (Joseph, 1982; McGuire, 1985). Although there are a number of moderating influences (e.g., fit with product and audience; low versus high purchase decision; prior attitudes), in general, the more trustworthiness, expertise, and or attractiveness the endorser has the more effective they are at changing consumer attitude and opinion (Brinol et al., 2004; Gotlieb and Sarel, 1991; Grewal et al., 1994; Harmon and Coney, 1982; Hovland et al., 1953; Hovland and Weiss, 1951; Sternthal et al., 1978).

Empirical evidence in support of source credibility is abundant. Source credibility is credited with improved consumer confidence (Brinol et al., 2004), reversing negative predispositions (Sternthal et al., 1978), increasing product purchase intentions (Harmon and Coney, 1982), and altering consumers' reactions to advertisements and brands (Goldsmith et al., 2000). Additionally, research has shown that highly credible sources "induce more behavioral compliance than do less credible sources" (Ohanian, 1990, p.42); in short, the source credibility literature provides strong evidence to suggest that the more credible a source is the more effective they are at endorsement.

Empirical support for source attractiveness is limited and at times contradictory. For example, physically attractive communicators are more liked than unattractive communicators (Joseph, 1982). Kahle and Homer (1985) found that source attractiveness enhanced brand recall in advertisements and led to a change in attitude and purchase intentions. Endorsers presenting products that were congruent with their image appeared more attractive than when presenting products that did not fit with their image, interestingly, this effect was only found with celebrity endorsers (i.e., not in non-celebrity endorsers) (Kamins and Gupta, 1994). Ohanian (1991), on the other hand, found that attractiveness was not significant in altering purchase intentions although expertise was. Ohanian's (1991) finding, although interesting, did not rule out the possibility that attractiveness indirectly influenced effectiveness. For instance, Kamins (1990) hypothesised and found evidence that physical attractiveness of a celebrity only enhances product and ad based evaluations when there is a close match between product and celebrity.

It can be said that source trustworthiness, source expertise and source attractiveness (see Figure 1) are relevant dimensions when selecting celebrity endorsers, although the importance of these dimensions are not equal; source trustworthiness and expertise are likely to have a larger impact on the effectiveness of an endorser than source attractiveness (Shimp, 1997). Collectively referred to as the source models (McCracken, 1989), expertise, trustworthiness and attractiveness represent the three most important dimensions heretofore in our understanding of celebrity endorser effectiveness (Ohanian, 1990). Research has shown that as factors in the source models increase, so too does the effectiveness of celebrity endorsers (McGuire, 1985; Miller and Basehart, 1969; Till and Busler, 1998). 
Figure 1 Three dimensions of celebrity endorser credibility scale

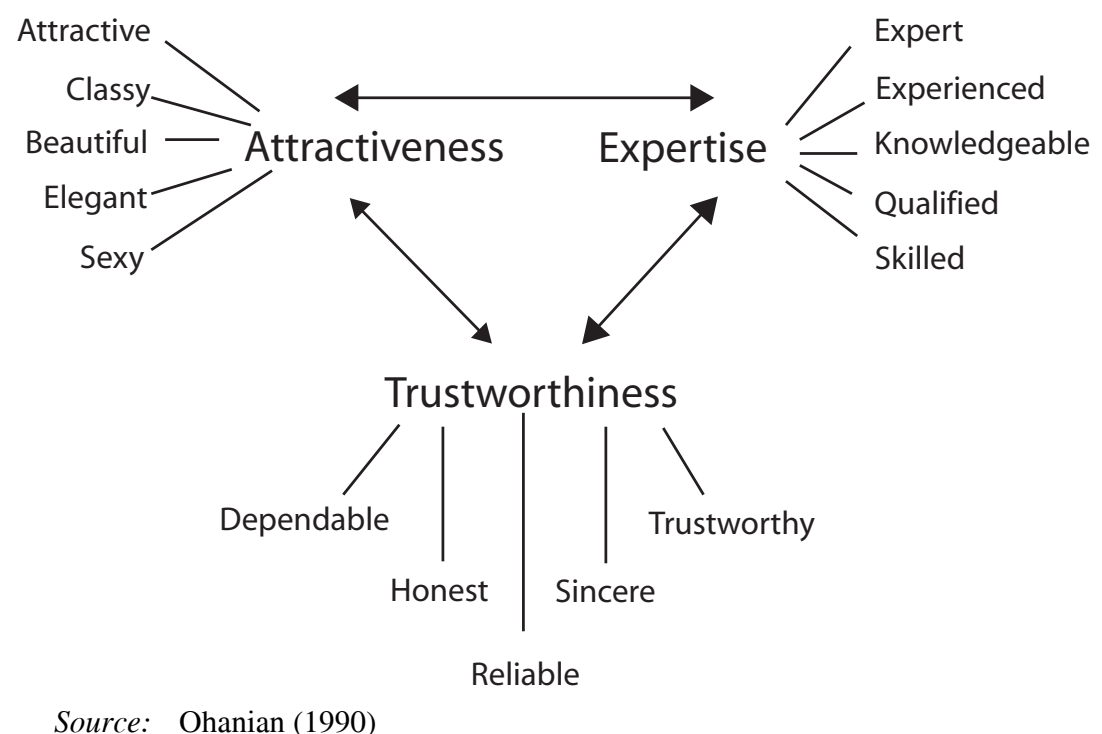

\subsection{Celebrity entrepreneurship and the role of involvement}

At the time the source models were conceptualised there was little reason to differentiate between the various forms of celebrity endorsement. It is apparent from looking at previous research that an overly narrow view of celebrity endorsement was assumed; one where endorsement was a more or less homogenous activity (i.e., brand representative, spokesperson, and 'all-round' endorser). The result of this view is that celebrities were compared on perceived personal characteristics or dispositions, such as their attractiveness, expertise, and trustworthiness (Cronley et al., 1999). When the time came for researchers to do their experiments, they held constant the activities of 'celebrity endorsement' and manipulated the differences in personal characteristics (Atkin and Block, 1983; Friedman and Friedman, 1979; Friedman et al., 1978; Friedman et al., 1976; Goldsmith et al., 2000; Kamins et al., 1989; O’Mahony and Meenaghan, 1998; Ohanian, 1991).

Today however, thanks largely to media reports, it is clear that celebrities are not a homogenous group of endorsers. Rather the activities they engage in range from simple endorsement where the celebrity is paid to associate themselves with a brand, all the way to celebrity entrepreneurship, which might include investing, ownership, product development and other operational responsibilities.

If we accept the view that celebrities are engaging in heterogeneous endorsement activities, then the existing source models are incomplete. This is because they make no consideration for situational factors, nor do they attempt to link observable events to their underlying motivational causes. It therefore makes little sense to hold these conditions constant in an experiment. For example, consumers are often measured on their attitudes towards ads and/or brands and perceptions of endorser trustworthiness, expertise and attractiveness; since conditions relevant to endorsement activities are held constant, the situational relationship between celebrity and product is hidden. In other words, 
researchers were measuring Attitude Towards the ads (Aad) and Attitude Towards the brands (Abr) and asking experimental participants to tell them if a celebrity is trustworthy in the things they say about, or an expert on a particular product, without informing them if the celebrity uses the product, has experience with the product, are paid to use the product, or are investors in the product, etc. Any one of these additional pieces of situational and dispositional information could alter a participants' opinion (directly or indirectly), which may affect the communicator (see e.g., Cronley et al., 1999; Robertson and Rossiter, 1974; Silvera and Austad, 2004).

The source models then are criticised through an attribution theory perspective, that attempts to explain the relative contributions to behaviour of situational and dispositional factors (Gilbert and Malone, 1995). The basic idea of attribution theory is easy to understand yet difficult to communicate, however Gilbert and Malone (1995, p.21) provide a skillful example to aid in this purpose:

\begin{abstract}
"People care less about what others do than about why they do it. Two equally rambunctious nephews may break two equally expensive crystal vases at Aunt Sofia's house, but the one who did so by accident gets the reprimand and the one who did so by design gets the thumbscrews. Aunts are in the business of understanding what makes nephews act as they do, and social psychologists are in the business of explaining how aunts achieve these understandings. The theories that provide these explanations are known as attribution theories."
\end{abstract}

Attribution $(\mathrm{al})^{2}$ theory is (in part) concerned with the consequences of these attributions (Kelly and Michela, 1980). As the example above attempts to convey, individuals are motivated to assign observable events to their underlying cause so that they may better order, organise, and thus understand their environment (Smith and Hunt, 1978).

When any event occurs and we try to explain the reason for that events occurrence, we assign either an internal or external reason. An external attribution is made when the cause is assigned to an external force, such as 'God told me to do it', or 'they did it for the money'. When an internal attribution is made the cause is assigned to some internal factors within the individual; making that person directly responsible. To help illustrate internal and external attributions, imagine the scenario of someone bumping into you: Your reaction would be measured based on if you believed the person did it intentionally (internal) to be mean, or because they tripped (external). If you believed the former, you may respond with some unkind words; however if you believe the latter to be true, i.e., it was an accident, you may even apologise for their mistake. A similar cognitive process may work in celebrity endorsement: If you watch a commercial and you believe the celebrity is telling you to buy a product because they are paid large sums of money (external), you may form a negative Aad and Abr; however if you believed that they used the product, liked the product, or even designed the product (internal), a more positive attitude may form.

Although attribution theory is rarely applied to the celebrity endorsement phenomenon, the findings are interesting. A study by Silvera and Austad (2004) used correspondence bias $^{3}$ to examine whether consumers infer that celebrity endorsers like the products they endorse. The consequence of consumers inferring celebrities liked the products they endorsed was a more positive attitudes towards the product. In a similar study, Cronley et al. (1999) found that as inferences about a celebrity's brand attitude became more favourable, the consequence was that consumers' Aad, Abr, and endorser favourably increased. These support the notion that when claims made by celebrities are attributed to internal factors, they are more effective endorsers. 
Eagly et al. (1978) as cited in Kelly and Michela (1980) found that both internal and external factors are taken into consideration when audience members view a communications message. In fact, by grade $\mathrm{V}$ children are able to make the distinction between internal and external attribution and to some extent already in the first grade (Robertson and Rossiter, 1974). The findings in these studies indicate that individual behaviour is to an extent dependent on attributional processes (Smith and Hunt, 1978).

As a paid endorser for a company, it is not entirely obvious that involvement should be anything more than a superficial association with the product. Celebrity entrepreneurship on the other hand should invoke, in the minds of consumers, a deeper relationship between celebrity and endorsed product. The celebrity is not simply endorsing the product, they are the product. As celebrities become more and more involved with the products they endorse, we expect that consumers will attribute more of the claims to the celebrity (internal factors) than to an external source (such as large monetary incentives), which in turn should directly increase the Aad and Abr. We have chosen to operationalise Involvement (also explained in the Results section) using several involvement items which have either been examined previously in the literature (such as liking for and using the product), and factors associated with entrepreneurship that are commonly reported in media outlets. Based on our belief that involvement has a direct effect on Aad and Abr, we include a 'more complete source model' (see Figure 2). We view liking for the product and using the product as emotional involvement by the communicator, which in Silvera and Austad's (2004) article relate to correspondence inferences. Information on ownership, managerial and operational status we believe represents entrepreneurial involvement.

Figure 2 A more complete source model

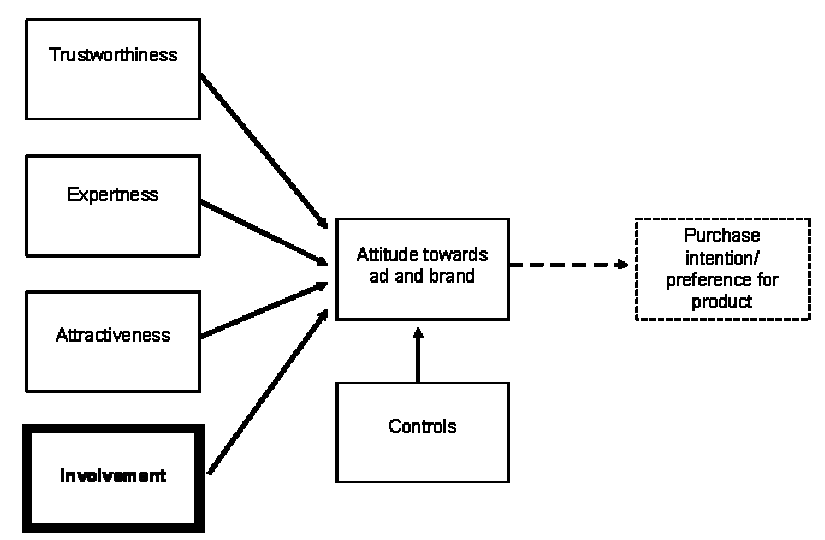

Based on the discussion above, we suggest and test the following hypotheses:

H1 Involvement is a conceptually and empirically distinct characteristic of communicators relative to the traditional characteristics trustworthiness, attractiveness and expertise.

H2 Higher Perceived involvement leads to higher communication effectiveness as manifested in 
H2a more positive attitude towards the $\mathrm{ad}$, and

$\mathrm{H} 2 \mathrm{~b}$ more positive attitude towards the brand.

H3 When the celebrity-communicator is involved in the capacity of an entrepreneur, perceived involvement increases

$\mathrm{H} 3$ a relative to when explicit information is given that the communicator is 'just' an endorser, as well as

$\mathrm{H} 3 \mathrm{~b}$ relative to when no information is given concerning the nature of the communicator's involvement.

\section{Method}

\subsection{Participants}

Two separate experiments were conducted on 88 and 77 first semester, Swedish university students. The participants were all part of the same course, however due to the large volume of students, the course was split into two groups. The first group of 88 participants consisted of 22 males and 66 females with an average age of 26. In addition to this, $90 \%$ of the respondents indicated that Swedish was their native tongue. The second group of 77 participants consisted of 23 males and 54 females, with an average age of 23. In this group, $92 \%$ claimed Swedish as their native language. The experiments were run during the first lecture of a methods course given to all first year students in the university's teaching programme. Participation was voluntary. Instructions were given to leave the questionnaire blank should anyone choose not to participate. In both experiments, there was $100 \%$ participation; in addition to this, all questionnaires were correctly filled in and used in the subsequent analyses.

\subsection{Materials and procedure}

Participants were randomly assigned to one of three experimental groups. Participants in each group were given an eight page 'experiment package' printed on black and white A4 paper written in Swedish. Each package contained:

- instructions

- demographic questions

- one of three experimental manipulations (including cover story)

- a celebrity advertisement

- a questionnaire.

Effort was made to ensure that each experiment package was identical in every way except for the (single paragraph) manipulation. The experiment package was originally written in English and translated to Swedish. To ensure the translation was accurate, a separate translator did a back-translation to English. The original English and back-translated English versions were then compared for discrepancies. A pilot study, 
using 13 colleagues was conducted to identify any errors or possible confusing information or questions in the experiment package. The outcome of this pilot study was that the question scales were reversed and several spelling mistakes corrected.

\subsection{Instructions}

On the cover page, simple information and instructions were given regarding the experiment. Participants were asked to answer all questions in the survey and were provided with one example of a question (unrelated to the experiment) and how it could be answered. After each section in the experiment, a reminder was given in bold type and 26-point font to see that all questions were answered. Participants were also reminded not to return to a section once they turned the page. This piece of information was given specifically so participant did not return to the main questions after reading the manipulation check questions.

\subsection{Manipulation}

Participants were randomly assigned to one of three experimental groups. As we mentioned previously, the experimental manipulation consisted of a one paragraph piece of information. Group one participants received the following information:
"Guppygear is a newly founded company by celebrity and now entrepreneur Cameron Diaz. In addition to appearing in TV, Radio, and printed advertisements, Diaz runs the company and designs the snowboards, equipment and clothes. As a co-owner of Guppygear, Diaz risks losing her investment if the company is not successful, but if the company is a success, Diaz's shares will be very valuable."

The group one manipulation was intended to represent Cameron Diaz as a typical entrepreneur. The second group of participants received the following information that depicted Diaz as a typical endorser:

"Guppygear is a newly founded company that has enlisted the help of Cameron Diaz to endorse their new line of snowboards, equipment and clothes. Her responsibilities are limited to appearing in TV, Radio, and printed ads. As compensation, Diaz receives a sizeable yet undisclosed payment."

Group three acted as our control group, and was given no information as to Diaz's connection with Guppygear.

Directly following the experimental manipulation, a cover story was presented to all groups claiming the purpose of the experiment is to establish the effectiveness of Guppygear's positioning strategy. Finally, a printed link to the fictional Guppygear homepage was given along with the expected North American and European launch dates.

\subsection{Celebrity advertisement}

In the first experiment, participants were given a black and white advertisement for a new company called 'Guppygear snowstuff' (see Figure 3). To help ensure that the advertisement appeared realistic, an expert was hired to create the advertisement using Photoshop. The fictitious advertisement pictured the celebrity Cameron Diaz (her face is 
blurred for this article), wearing a winter jacket, back-dropped by a professional snowboarder in mid-flight. On the opposite side of Diaz are small pictures of the 'Guppygear snowstuff' equipment; including a snowboard, glove, boot, and jacket. At the top of the advertisement the words 'Boards - Boardies - Outfits' appears. In the middle of the ad, the logo for 'Guppygear snowstuff' is shown, and finally at the bottom a quote that is supposed to be inferred as coming from Diaz is at the bottom: "Whether I am snowboarding or hanging with my friends, Guppygear is the perfect combination of style, comfort and quality". This caption was then translated into Swedish and appeared directly to the right of the advertisement. This was intentionally done to ensure understanding and to maintain the credibility of the advertisement - in Sweden, advertisements for US companies are often left in the original English.

Figure 3 Ad copy used for the fictional 'Guppygear snowstuff' company in experiment one

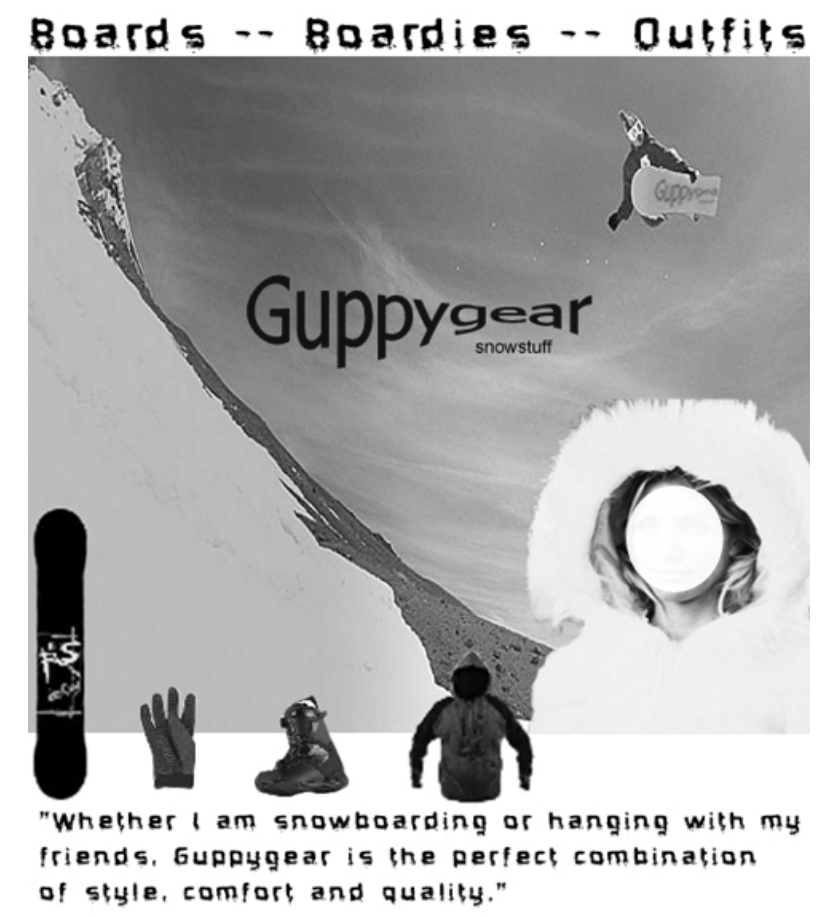

The second experiment was nearly identical to the first except for the advertisement used and the name of the company. In this experiment, Cameron Diaz was used, only this time she was pictured in fictitious ads for the 'Guppygear surfstuff' company. In addition to this, two ads instead of one were shown side by side (see Figure 4). This was done to increase the plausibility of the cover story; which was to evaluate the positioning strategy of Guppygear and also to raise the believability of the advertisements. The caption in the first ad where Diaz is holding her surfboard reads the same as in the 'Guppygear snowstuff' ad. The second ad, where a 'cartoon' version of Diaz is riding a pipeline, has a slightly different caption "When I hit the beach, I look for my Guppygear surfstuff. It is the perfect blend of style, comfort, and quality". Once again to the right of the advertisements was a Swedish translation. 
Figure 4 Ad copies used for the fictional 'Guppygear surfstuff' company in experiment two
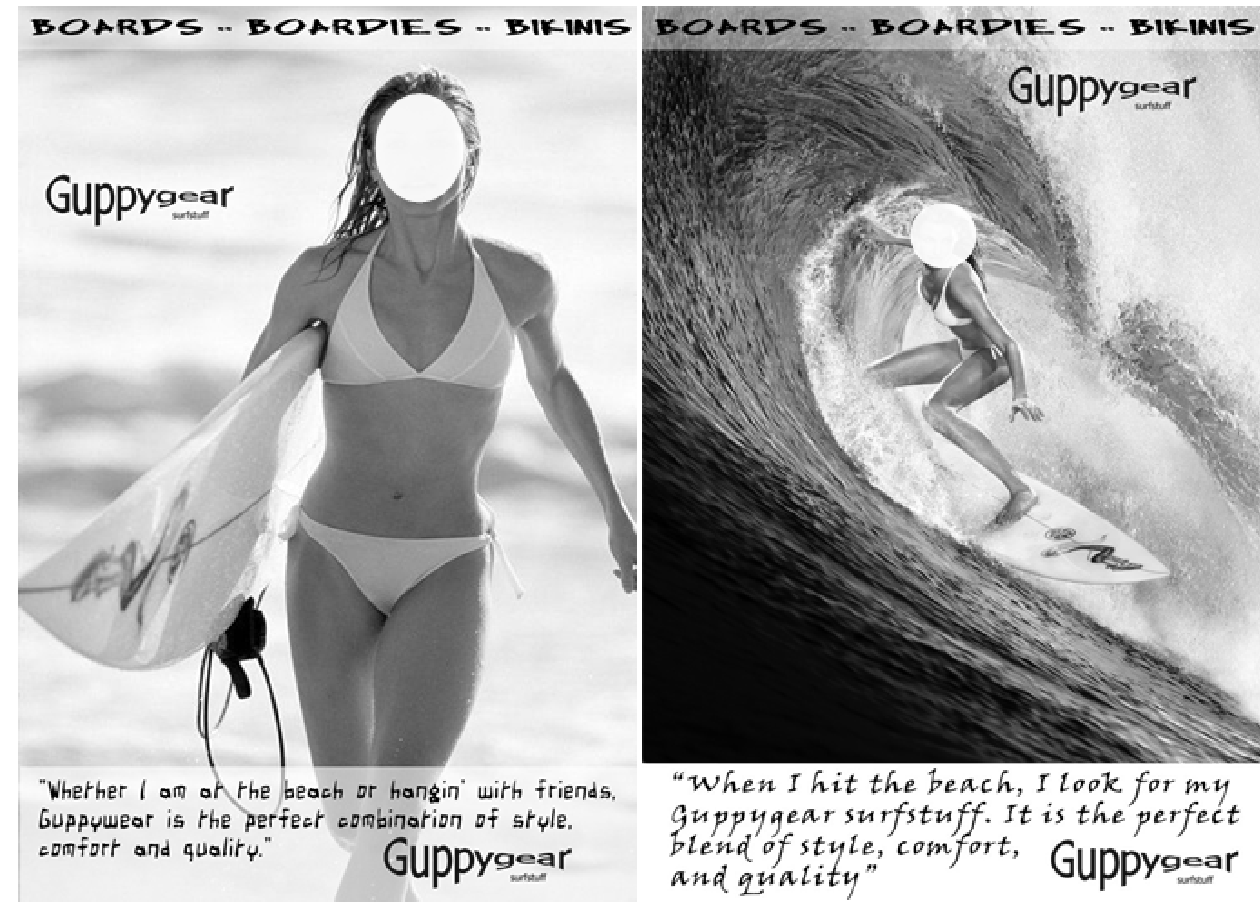

\subsection{Measures}

The questionnaire consisted of three parts. Part one covered demographic questions; part two of the questionnaire was designed to measure the dependent variables of interest, followed by a third part which was used as a manipulation check.

Each participant was asked to indicate their gender, age, native tongue, and whether or not they had heard of Cameron Diaz previously. These questions were asked before the experimental manipulation was given and before any other questions were administered so they could later be used as covariates or control variables.

Trustworthiness, expertise, and attractiveness were operationalised using Ohanian's (1990) validated scale and seven-point semantic differential scale measurements. To measure trustworthiness, participants were asked "In relation to this advertisement Cameron Diaz is:", followed by five different measures for trustworthiness (undependable-dependable; dishonest-honest; unreliable-reliable; insincere-sincere; untrustworthy-trustworthy). Internal reliability for both experiments was satisfactory $(\alpha=.914$ and $\alpha=.929)$. Expertise was measured by asking participants "In relation to these products Cameron Diaz is:", followed by measures for expertise (not an expert-expert; inexperienced-experienced; unknowledgable-knowledgable; unqualified-qualified; unskilled-skilled. Internal reliability was satisfactory $(\alpha=.914$ and $\alpha=.911$ ) Attractiveness was measured by asking: "Would you say that Cameron Diaz is:" again followed by five measurements (unattractive-attractive; not classy-classy; ugly-beautiful; plain-elegant; not interesting-interesting). Here too, internal reliability was acceptable $(\alpha=.814$ and $\alpha=.840)$. 
Aad was operationalised using MacKenzie et al.'s (1986) scale by asking participants "What is your overall reaction to the advertisement for Guppygear?", followed by three measurements on a seven point semantic differential scale (unfavourable-favourable; bored-interested; bad-good). In addition to this, one further question was posed to measure Aad: "In general, how effective is the ad for Guppygear" followed with one measure on a seven point semantic differential scale (extremely ineffective-extremely effective). Internal reliability ( $\alpha=.875$ and $\alpha=.894)$.

Abr was operationalised using the MacKenzie et al. (1986) scale by asking participants: "What is your overall feeling about using Guppygear products?", followed by three measurements on a seven point semantic differential scale (unfavourable-favourable; bad-good; foolish-wise). In addition to this, one further question was posed to measure Abr: "Overall how appealing to you is Guppygear" followed with one measure on a seven point semantic differential scale (extremely low appeal-extremely high appeal). Internal reliability $(\alpha=.882$ and $\alpha=.894)$.

The operationalisation of involvement will be thoroughly explained in the results section. To measure this, participants were asked two questions for each: Liking for the product was determined by asking participants to respond to the statements "Cameron Diaz is enthusiastic about Guppygear products" and "Cameron Diaz really likes Guppygear products" ( $\alpha=.895$ and $\alpha=.884)$. Usage of the products was determined by measuring the reaction to the statements "Cameron Diaz often uses Guppygear products" and Cameron Diaz believes using Guppygear products is good" ( $\alpha=.773$ and $\alpha=.820$ ).

The questionnaire ended with two manipulation check questions: "I believe that Cameron Diaz's engagement in Guppygear is more than simple endorsement" and "Cameron Diaz's engagement in the Guppygear company is only in an endorser capacity" served two purposes. First, responses to these questions allowed us to measure the inferred level of Cameron Diaz's involvement in Guppygear which could then be used as an additional dependent variable, and second, responses to these questions served as manipulation checks.

\section{Results}

Our first hypothesis states that involvement is conceptually and empirically distinct from the traditional Source Model characteristics attractiveness, trustworthiness and expertise. In order to be able to test this hypothesis we included in this research the five items in Table 1. As can be seen, the items seem capable of capturing variance among the respondents. The full range is used for most of the items and the mean is close to the mid-point of the scale.

In order to determine whether the items in the index capture the same construct we performed a test of internal consistency using the Reliability routine in SPSS. This analysis yielded very high Cronbach Alpha values for the index, 0.89 and 0.86 in Experiments 1 and 2, respectively. These are highly satisfactory levels of internal consistency for this type of measure (Nunnally, 1967; Nunnally and Bernstein, 1994). No deletion of items would further enhance the Cronbach's Alpha value. However, this alone does not demonstrate that the measure of involvement is distinct from the traditional Source Model constructs. In order to test for discriminant validity we performed separate exploratory factor analyses for the two samples, using all Trustworthiness, Attractiveness and Expertise items alongside our own Involvement items. For our purpose, the ideal 
result of such an analysis would be: four factors with an Eigenvalue greater than unity and a loading pattern where each item loads highly on its corresponding theoretical factor and at the same time gets a low loading on all other factors. A minimum requirement in relation to Hypothesis 1 is that a factor clearly reflecting 'Involvement' can be extracted. The results are displayed in Table 2.

The results demonstrate that in line with expectation, four factors corresponding to the default Eigenvalue $>1$ criterion was extracted in each analysis. Further, the loading patterns are very clear. Each item consistently has the highest loading on the expected factor, and there are very few 'side loadings' of non-negligible magnitude. By and large, the explained variance is as high, and the loading pattern as clear, for the Involvement factor as for the well established Trustworthiness, Attractiveness and Expertise constructs. In combination with the high Cronbach's Alpha we regard this as clear support for Hypothesis 1: Involvement is a conceptually and empirically distinct characteristic of communicators.

The factor analysis forces orthogonality and hence is able to demonstrate that the (now) four dimensions of the Source Model (Figure 2) can be regarded as distinct. If, however, four summated indices are created on the basis of the four five-item batteries it is revealed that the four constructs also share common variance. The zero-order correlations among four indices thus computed range from 0.20 to 0.58 , and the multiple correlations are even higher than that. This means that it is difficult to discern the unique effect of each dimension if such indices were entered as explanatory variables in a multiple regression analysis. By contrast, factor scores are uncorrelated by definition. Therefore, in order to be better able to assess the unique effect of Involvement we use the factor scores rather than summated indices in subsequent analyses.

Table 1 Wording and descriptive statistics for involvement items

\begin{tabular}{lcccc}
\hline \multirow{2}{*}{ Item } & \multicolumn{4}{c}{ Statistics for Experiment 1 } \\
\cline { 2 - 5 } Cameron Diaz is enthusiastic about Guppygear products & 1 & 7 & 3.6 & 1.6 \\
Cameron Diaz likes Guppygear products & 2 & 7 & 3.9 & 1.5 \\
Cameron Diaz uses Guppygear products often & 1 & 7 & 3.3 & 1.4 \\
$\begin{array}{l}\text { Cameron Diaz believes it is good to use Guppygear } \\
\text { products }\end{array}$ & 1 & 7 & 4.1 & 1.4 \\
$\begin{array}{l}\text { I believe Cameron Diaz's engagement in Guppygear is } \\
\text { more than an endorser }\end{array}$ & 1 & 7 & 3.5 & 1.6 \\
& & & & \\
Cameron Diaz is enthusiastic about Guppygear products & 1 & 7 & 4.3 & 1.4 \\
$\begin{array}{l}\text { Cameron Diaz likes Guppygear products } \\
\text { Cameron Diaz uses Guppygear products often }\end{array}$ & 2 & 7 & 4.5 & 1.4 \\
$\begin{array}{l}\text { Cameron Diaz believes it is good to use Guppygear } \\
\text { products }\end{array}$ & 2 & 7 & 3.8 & 1.5 \\
$\begin{array}{l}\text { I believe Cameron Diaz's engagement in Guppygear is } \\
\text { more than an endorser }\end{array}$ & 1 & 7 & 3.7 & 1.3 \\
\hline
\end{tabular}


In order to test Hypothesis 2 we performed a series of hierarchical multiple regression analyses. Starting with the Experiment 1 data and Aad as dependent variable, we first entered in Model 1 four potentially influential control variables in the first step: Age (years), Gender ( $1=$ male; $2=$ female $)$, Country of origin $(1=$ Swedish as mother tongue; $0=$ else $)$ and Prior Familiarity with Cameron Diaz $(0=$ No; $1=$ A little; $2=\mathrm{A}$ lot $)$. In Model 2 the traditional Source Model variables were entered (as operationalised with factor scores), and in Model 3 we finally add the Involvement factor score. In this way we require for $\mathrm{H} 3$ to be regarded as supported that Involvement has an effect over and above what can be explained by the controls and the traditional Source Model dimensions. In Models 4 to 6 we repeat the procedure with Abr as dependent variable. Finally, in estimating Models 7-12 we repeat the whole sequence using the data from Experiment 2. The results are displayed in Table 3.

Table 2 Factor analysis of all trustworthiness, attractiveness, expertise and involvement items

\begin{tabular}{|c|c|c|c|c|}
\hline Factor no. & Factor 1 & Factor 2 & Factor 3 & Factor 4 \\
\hline Name & Expertise & Trustworthiness & Involvement & Attractiveness \\
\hline (Var. expl. after rotation) & $(20 \%)$ & $(19 \%)$ & $(18 \%)$ & $(16 \%)$ \\
\hline \multicolumn{5}{|l|}{ Variable } \\
\hline \multicolumn{5}{|l|}{ Experiment $1(\mathrm{n}=88)$} \\
\hline Expertise 1 & 0.87 & & & \\
\hline Expertise2 & 0.86 & & & \\
\hline Expertise3 & 0.83 & & & \\
\hline Expertise4 & 0.82 & & & \\
\hline Expertise5 & 0.80 & & & \\
\hline Trustworthiness1 & & 0.85 & & \\
\hline Trustworthiness2 & & 0.85 & & \\
\hline Trustworthiness3 & & 0.82 & & \\
\hline Trustworthiness4 & & 0.80 & & \\
\hline Trustworthiness5 & 0.35 & 0.75 & & \\
\hline Involvement1 & & & 0.88 & \\
\hline Involvement2 & & & 0.85 & \\
\hline Involvement3 & & & 0.81 & \\
\hline Involvement4 & & & 0.80 & \\
\hline Involvement5 & & & 0.65 & \\
\hline Attractiveness1 & & & & 0.79 \\
\hline Attractiveness 2 & & & & 0.78 \\
\hline Attractiveness 3 & & & & 0.78 \\
\hline Attractiveness 4 & & & & 0.77 \\
\hline Attractiveness5 & & & & 0.74 \\
\hline
\end{tabular}


Table 2 Factor analysis of all trustworthiness, attractiveness, expertise and involvement items (continued)

\begin{tabular}{|c|c|c|c|c|}
\hline Factor no. & Factor 1 & Factor 2 & Factor 3 & Factor 4 \\
\hline Name & Expertise & Trustworthiness & Involvement & Attractiveness \\
\hline (Var. expl. after rotation) & $(18 \%)$ & $(20 \%)$ & $(17 \%)$ & $(17 \%)$ \\
\hline \multicolumn{5}{|l|}{ Variable } \\
\hline \multicolumn{5}{|l|}{ Experiment $2(\mathrm{n}=77)$} \\
\hline Expertise1 & 0.84 & & 0.33 & \\
\hline Expertise 2 & 0.81 & & & \\
\hline Expertise 3 & 0.78 & & 0.33 & \\
\hline Expertise 4 & 0.75 & & & \\
\hline Expertise 5 & 0.70 & & & \\
\hline Trustworthiness 1 & & 0.89 & & \\
\hline Trustworthiness 2 & & 0.88 & & \\
\hline Trustworthiness 3 & & 0.85 & & \\
\hline Trustworthiness4 & & 0.84 & & \\
\hline Trustworthiness5 & & 0.81 & & \\
\hline Involvement 1 & & & 0.87 & \\
\hline Involvement 2 & & & 0.83 & \\
\hline Involvement 3 & & & 0.78 & \\
\hline Involvement 4 & & & 0.70 & \\
\hline Involvement5 & & & 0.55 & \\
\hline Attractiveness 1 & & & & 0.86 \\
\hline Attractiveness 2 & & & & 0.81 \\
\hline Attractiveness3 & & & & 0.80 \\
\hline Attractiveness 4 & & & & 0.79 \\
\hline Attractiveness5 & & & & 0.54 \\
\hline
\end{tabular}

Note: Both analyses clearly favour a four factor solution. Eigenvalues for the fourth and fifth (non-extracted) factors are 1.87 versus 0.85 in Experiment 1, and 1.49 versus 0.89 in Experiment 2. Principal Component extraction and Varimax rotation were employed. Loadings smaller than \pm .30 have been suppressed. Factors were numbered as they came out in the original analysis in Experiment 1.

The results show that while some of the control variables come out significant when entered separately their effects lack consistency and do not hold up when all the Involvement variables are entered. As expected, the traditional Source Model variables come out with a significant positive effect and contribute substantively to explanatory power in each analysis. Importantly, the same holds for Involvement when entered after Trustworthiness, Attractiveness and Expertise. The coefficient is statistically significant in each analysis, and this variable is ascribed a unique contribution to explanatory power of $8 \%$ on average, with a range from $3 \%$ to $14 \%$. The average unique 
contribution ascribed to the traditional Source Model variables is about $6.5 \%$. The effect of Involvement holds up in both experiments and for both Aad and Abr as dependent variable. While the effect of Involvement varies across the analyses it is consistently positive and significant, and we do not find reasons to speculate about substantive reasons for the variance in the estimated magnitude of the effect. This variation may well be stochastic.

Table 3 Regression analyses assessing the effects of involvement

\begin{tabular}{|c|c|c|c|c|c|c|}
\hline \multicolumn{7}{|c|}{ Experiment $1(n=88)$} \\
\hline \multirow{2}{*}{$\begin{array}{l}\text { Dependent variables } \\
\text { Independent variables }\end{array}$} & \multicolumn{3}{|c|}{ Attitude towards ad } & \multicolumn{3}{|c|}{ Attitude towards brand } \\
\hline & Model 1 & Model 2 & Model 3 & Model 4 & Model 5 & Model 6 \\
\hline \multicolumn{7}{|l|}{ Controls } \\
\hline Age & -.05 & -.09 & -.11 & -.01 & -.11 & -.12 \\
\hline Gender & .06 & -.07 & .00 & .13 & -.07 & -.01 \\
\hline Country of origin & $.24^{*}$ & $.21 *$ & .14 & .24 & .04 & -.01 \\
\hline Prior familiarity & .10 & -.08 & -.07 & .23 & .02 & .02 \\
\hline \multicolumn{7}{|l|}{ Source model variables } \\
\hline Trustworthiness & & $.26 * *$ & $.25^{* *}$ & & $.29 * *$ & $.29 * *$ \\
\hline Attractiveness & & $.35 * * *$ & $.34 * * *$ & & $.25 *$ & $.24 * *$ \\
\hline Expertise & & $.32 * * *$ & $.30 * * *$ & & $.32 * *$ & $.30 * *$ \\
\hline Involvement & & & $.39 * * *$ & & & $.31 * * *$ \\
\hline Adj. $R^{2}$ & .04 & .26 & .41 & .00 & .19 & .28 \\
\hline $\mathrm{R}^{2}$ change (unadj.) & .09 & $.24 * * *$ & $.14 * * *$ & .04 & $.21 * * *$ & $.09 * * *$ \\
\hline \multicolumn{7}{|c|}{ Experiment $2(n=77)$} \\
\hline Dependent variables & \multicolumn{3}{|c|}{ Attitude towards ad } & \multicolumn{3}{|c|}{ Attitude towards brand } \\
\hline Independent variables & Model 7 & Model 8 & Model 9 & Model 10 & Model 11 & Model 12 \\
\hline \multicolumn{7}{|l|}{ Controls } \\
\hline Age & -.09 & -.05 & -.06 & .10 & .14 & .12 \\
\hline Gender & .16 & $.21 *$ & .16 & .09 & .10 & .07 \\
\hline Country of origin & -.13 & .00 & .02 & -.13 & -.03 & -.04 \\
\hline Prior familiarity & $.39 * * *$ & .20 & .12 & $.39 * * *$ & .22 & .17 \\
\hline \multicolumn{7}{|l|}{ Source model variables } \\
\hline Trustworthiness & & $.23 *$ & $.25^{* *}$ & & $.25^{*}$ & $.27 * *$ \\
\hline Attractiveness & & $.29 * *$ & $.30 * *$ & & $.23^{*}$ & $.24 *$ \\
\hline Expertise & & $.35 * * *$ & $.35 * * *$ & & $.20 *$ & $.20 *$ \\
\hline Involvement & & & $.26^{* *}$ & & & $.19 *$ \\
\hline Adj. $R^{2}$ & .17 & .35 & .41 & .11 & .20 & .23 \\
\hline $\mathrm{R}^{2}$ change (unadj.) & $.21 * *$ & $.20 * * *$ & $.06^{* *}$ & $.16^{*}$ & $.12 * *$ & $.03 *$ \\
\hline
\end{tabular}

Notes: $\quad *=\mathrm{p}<0.05$.

$* *=\mathrm{p}<0.01$.

$* * *=\mathrm{p}<0.001$

Reported significance levels are single-tailed for Source Model variables and two-tailed for control variables. The displayed coefficients are standardised Betas. 
In summary, the results are clearly in support of Hypothesis 2 (both $a$ and $b$ ). Higher perceived Involvement leads to higher communication effectiveness and is manifested in more positive Aad and Abr. Moreover, these effects are of comparable magnitude to the corresponding effects of the well established Source Model variables Trustworthiness, Attractiveness and Expertise.

Now let us turn to the important question of whether our experimental manipulation had the expected effect on perceived involvement. Our third hypothesis stated that when the celebrity communicator is involved in the capacity of an entrepreneur, perceived involvement increases relative to when explicit information is given that the celebrity communicator is 'just' an endorser and when no information is given. To test this hypothesis, a $1 \times 3$ between group Analysis of Variance (ANOVA) was used, where one factor was varied under three experimental conditions (entrepreneur, endorser, and control group) as a between subjects variable. Support for our theory would be indicated if scores for Involvement were higher in the groups exposed to the entrepreneur condition versus those in the endorser and control group.

There was a statistically significant difference at the $\mathrm{p}<.05$ level in Involvement scores for the three groups in Experiment $1[\mathrm{~F}(2,85)=6.584, \mathrm{p}=0.002]$ and Experiment $2[\mathrm{~F}(2,74)=9.270, \mathrm{p}=0.000]$. In addition to reaching statistical significance for Involvement, the actual difference in mean scores between the groups was medium and large for the two experiments. The effect size of .13 and .20 for Experiments 1 and 2, respectively, were calculated using eta squared. According to Cohen (1988) a medium effect size is reached at .06 and a large effect size at .14.

A planned comparison in experiment one on Involvement between the experimental conditions for the entrepreneur group $(\mathrm{M}=4.22 \mathrm{SD}=1.44)$ and control group $(\mathrm{M}=3.73$ $\mathrm{SD}=1.02$ ) revealed a statistically significant difference $[\mathrm{F}(1,85)=2.50, \mathrm{p}=0.058]$. While the planned comparison between the entrepreneur group and endorser group $(\mathrm{M}=3.09, \mathrm{SD}=1.02)$ was statistically significant $[\mathrm{F}(1,85)=13.09, \mathrm{p}=0.0005]$, as was the planned comparison between the endorser group and control group $[\mathrm{F}(1,85)=7.98$, $\mathrm{p}=0.006]$. Similar results were found for experiment two. The comparison between the entrepreneur group $(\mathrm{M}=4.88, \mathrm{SD}=1.14)$ and endorser group $(\mathrm{M}=3.76, \mathrm{SD}=0.90)$ was significant $[\mathrm{F}(1,74)=15.58, \mathrm{p}=0.0005]$ as was the comparison between the entrepreneur group and control group $(\mathrm{M} 3.85, \mathrm{SD}=1.16) ;[\mathrm{F}(1,74)=11.86, \mathrm{p}=0.0005]$.

The ANOVA findings provide ample evidence to accept H3 (both $a$ and $b$ ). That is, when a celebrity communicator is perceived to be involved as an entrepreneur, perceived involvement increases more so than it does when explicit information is given that the celebrity is an endorser, and when no information is given.

\section{Discussion}

The most important finding from these experiments is the identification of a conceptually and empirically distinct characteristic of communicators that we call Involvement. What is more, we have shown that Involvement provides unique explanatory power, above and beyond, the extent source model predictors (source trustworthiness, expertise and attractiveness) of Aad and Abr. Importantly, we found that as entrepreneurial involvement increases, so to does perceived Involvement. This finding supports the view that entrepreneurial involvement by a celebrity communicator is an effective (and novel) way to enhance perceived involvement and ultimately improve Aad and Abr. 
We believe this represents the first empirical study into what we call the celebrity entrepreneurship phenomenon. Celebrity entrepreneurship, as the name implies, spans several research disciplines. It is therefore in the interest of several stakeholders to develop knowledge about how celebrity entrepreneurship works.

For new venture founders and marketers, the findings suggest that involving a celebrity more deeply with their products is one way to improve their customers' attitudes towards the ads in which they appear and the brands they sell. When a celebrity is truly involved at a deeper level than simple endorsement, it may behoove the company to communicate that information. Practitioners may also be well advised to consider new forms of endorsement contracts with celebrities - particularly fruitful may be those structured in a way that incentives are created for celebrities to increase their level of involvement with the brand and company. This advice however must be accompanied with a caveat. Involving a celebrity too much may cause consumers to view the celebrity and the brands they endorse as one and the same. This could become problematic if and when negative information surfaces about the celebrity (see e.g., Jacobson et al., 2001; Klebba and Unger, 1982; Louie and Obermiller, 2002), when celebrity fades, or in the event their image changes (Kaikati, 1987). This is something we plan to test in future experiments.

For researchers in entrepreneurship and marketing communication this study contributes new insights into phenomena within their respective domains. To the marketing communication literature we offer the identification and proven effect of an additional Source Model variable: Involvement. While this research demonstrated that celebrity entrepreneurship is one factor that increases perceived involvement we do not believe this variable is unique to a celebrity entrepreneurship context. Celebrity endorsers, and for that matter expert endorsers and the typical consumer endorser, all bring with them varying levels of involvement to the products they endorse. This variation, at least when made known to consumers, should affect Aad and Abr.

To entrepreneurship we contribute the opening up of research into a new, entrepreneurial phenomenon. In this context we regard 'celebrity capital' as a previously neglected, yet relevant resource dimension to consider. Celebrity entrepreneurship as a phenomenon represents billions of dollars each year in transaction costs and likely countless more in increased earnings for firms and tax revenues for governments. The businesses started, jobs created, and money transacted are just some of the reasons that celebrity entrepreneurship is an important phenomenon to study.

\section{Limitations}

At this point, we would like to share some of the limitations and difficulties encountered while conducting this study in the hope that our learning pains and mistakes can be avoided.

Our sample can be pointed out as a limitation for several reasons. First, we used a student sample for both experiments. In addition to this, our population comprised mainly Swedish students. Differences in attitudes towards celebrities and advertising in general could restrict the extent of our statistical generalisability (Silvera and Austad, 2004); it may very well be the case that our findings do not generalise well beyond a Swedish student population. In defence of this, we would like to point out that statistical generalisation was of secondary concern to theoretical generalisation (Mook, 1983). 
Ideally, we should have used different celebrities in our experiment; this would have increased the theoretical generalisability of our experiment. As it stands, we suspect that the celebrity chosen can impact the believability of one's involvement.

Although we took steps to ensure our translation from English to Swedish was done well, Swedish is a language of fewer words than English. As a result, some of the nuanced meanings from English did not translate as well as we would have liked. To counter this, we conducted a back translation, which despite our best efforts was acceptable, but not perfect.

Descriptive statistics revealed that our first experimental manipulation was not as strong as our second. Recall if you will, in the first experiment we only used one advertisement, which was subjectively of poorer quality than those used in the second experiment. Although the results from our experiments were not too dissimilar, our manipulation checks revealed our second experiment was more effective. We believe this was the case for two reasons. First, as we mentioned, the quality of the ads used in the second experiment was better which may have led to greater believability. Second, using two ads instead of one likely served to strengthen our cover story. This led to greater believability and probably reduced any demand characteristics.

While we hypothesised and found evidence that Involvement is an important factor in predicting Aad and Abr, we did not go into detail regarding the underlying mechanism for how this may work. Source trustworthiness, expertise and attractiveness are important factors in endorsement effectiveness because they may help facilitate the process of attitude and opinion change ${ }^{4}$ (Kelman, 1961). According to Kelman (1961), attitude and opinion change works in part by a process of identification and internalisation. If you find someone attractive you are more likely to identify with them. In an advertising context this would mean that the source of information (i.e., endorser) when attractive or likeable to the recipient, would be in a position to influence attitude and opinion (Desarbo and Harshman, 1985). If you find someone trustworthy or expert, you are likely to internalise what they say. When you identify with a person or internalise the things they say, in general your attitude and opinion should change in kind. Involvement may work in a similar fashion. The extent to which an actor is liked (attractive), trustworthy, or persuasive, is largely dependent on whether an action is attributed to that actor or to some aspect of their environment (Kelly and Michela, 1980). As Involvement increases, consumers may attribute the actions of endorsers to personal motivations, rather than exogenous forces. This then would, in theory, make the celebrity more likeable, trustworthy, and persuasive; all key elements in inducing identification and internalisation (Kelman, 1961). Perceived using and liking of the product would be reasons why someone would identify with the endorser and thus increase their Aad and Abr. The unique contribution of entrepreneurship may work through internalisation in that the endorser becomes more trustworthy and expert. Future studies, in addition to testing the direct effect Involvement has on Aad and Abr, should also look at the indirect effect Involvement may play in increasing an endorser's trustworthiness, expertise and attractiveness. 


\section{Conclusion}

A colleague of ours asked, half seriously, what would you say to an advertising executive if she were to walk into your office and ask for advice about hiring Cameron Diaz? Before this experiment, we may have suggested that she try to understand target customers' attitudes towards Diaz. If in general her customers trusted Diaz in relation to the things she had to say about the product it would be a good start. If the customers generally liked Diaz and found her attractive it would be great. And if customers also saw Diaz as some sort of expert in relation to the product, sign her up.

Upon reflection, this advice may have been limited. Our experiment revealed that perceived involvement is a distinct predictor of endorser effectiveness. As such, it would help our advertising executive to know if customers actually believed Diaz liked and used the product. One way she could increase this belief is by communicating any managerial and operational roles, or financial risks taken by Diaz for the product. This in turn may directly improve her customers' attitudes towards ads and brands which Diaz endorses.

As it were, we declined to answer our colleague's hypothetical question. Although we have found support for all of our hypotheses, more evidence in this empirical setting needs to accumulate before we start giving 'advice to the stars'. For the time being, we are content in our belief that involvement helps on the one hand to explain why celebrity entrepreneurship is successful, and on the other hand we believe it provides more explanatory power to the reasons behind endorsement effectiveness.

\section{References}

Atkin, C. and Block, M. (1983) 'An experiment revealed the effectiveness of celebrity endorsers', Journal of Advertising Research, 1 February-March, Vol. 23, pp.57-61.

Brinol, P., Petty, R. and Tormala, Z. (2004) 'Self-validation of cognitive responses to advertisements', Journal of Consumer Research, Vol. 30, No. 4, pp.559-574.

Chapman, S. and Leask, J-A. (2001) 'Paid celebrity endorsement in health promotion: a case study from Australia', Health Promotion International, Vol. 16, No. 4, pp.333-338.

Cohen, J. (1988) Statistical Power Analysis for the Behavioral Sciences, Hillside, NJ: Erlbaum.

Crano, W. (1970) 'Effects of sex, response order, and expertise in conformity: a dispositional approach', Sociometry, September, Vol. 33, pp.239-252.

Crisi, R. and Kassinove, H. (1973) 'Effects of perceived expertise, strength of advice, and environmental setting on parental compliance', The Journal of Social Psychology, Vol. 89, No. 2, pp.245-250.

Cronley, M.L., Kardes, F.R., Goddard, P. and Houghton, D.C. (1999) 'Endorsing products for money: the role of correspondence bias in celebrity advertising', Advances in Consumer Research, Vol. 26, pp.627-631.

Desarbo, W.S. and Harshman, R.A. (1985) 'Celebrity-brand congruence analysis', in J.H. Leigh and C.R. Martin (Eds.) Current Issues and Research in Advertising, University of Michigan, Michigan, Vol. 4, pp.17-52.

Dickenson, N. (1996) 'Can celebrities ruin a launch?', Campaign, 3 May.

Dow, H. (2005) George Foreman's Rise to the Top, http://www.cbsnews.com/stories/2005/08/13/ sunday/main776991.shtml (retrieved 27 August 2005).

Eagly, A.H., Wood, W. and Chaiken, S. (1978) 'Causal inferences about communicators and their effect on opinion change', Journal of Personality and Social Psychology, Vol. 37, pp.621-634. 
Erdogan, Z. (1999) 'Celebrity endorsement: a literature review', Journal of Marketing Management, Vol. 15, pp.291-314.

Friedman, H. and Friedman, I. (1976) 'Whom do students trust', Journal of Communication, Vol. 26, No. 2, p.48.

Friedman, H. and Friedman, L. (1979) 'Endorser effectiveness by product type', Journal of Advertising Research, Vol. 19, No. 5, p.63.

Friedman, H., Santeramo, M.J. and Traina, A. (1978) 'Correlates of trustworthiness for celebrities', Academy of Marketing Science, Fall, Vol. 6, pp.291-299.

Friedman, H., Termine, S. and Washington, R. (1976) 'The effectiveness of advertising utilizing four types of endorsers', Journal of Advertising, Vol. 5, No. 3, pp.22-24.

Gamson, J. (1994) Claims to Fame: Celebrity in Contemporary America, Berkeley: University of California Press.

Gilbert, D.T. and Malone, P.S. (1995) 'The correspondence bias', Psychological Bulletin, Vol. 117, No. 1, pp.21-38.

Goldsmith, R.E., Lafferty, B.A. and Newell, S.J. (2000) 'The impact of corporate credibility and celebrity credibility on consumer reaction to advertisements and brands', Journal of Advertising, Vol. 29, No. 3, pp.43-54.

Gotlieb, J. and Sarel, D. (1991) 'Comparative advertising effectiveness: the role of involvement and source credibility', Journal of Advertising, Vol. 20, No. 1, p.38.

Grewal, D., Gotlieb, J. and Marmorstein, H. (1994) 'The moderating effects of message framing and source credibility on the price-perceived risk relationship', Journal of Consumer Research, June, Vol. 21.

Harmon, R. and Coney, K. (1982) 'The persuasive effects of source credibility in buy and lease situations', Journal of Marketing Research, Vol. 19, pp.255-260.

Hovland, C. and Weiss, W. (1951) 'The influence of source credibility on communication effectiveness', Public Opinion Quarterly, Winter, Vol. 15, pp.635-650.

Hovland, C., Irving, J. and Kelly, H. (1953) Communication and Persuasion, New Haven, CT: Yale University Press.

Jacobson, R., Kulik, R.L. and Louie, T.A. (2001) 'When bad things happen to the endorsers of good products', Marketing Letters, Vol. 12, No. 1, pp.13-23.

Joseph, B. (1982) 'The credibility of physically attractive communicators: a review', Journal of Advertising, Vol. 11, No. 3, pp.15-24.

Kahle, L.R. (1984) Attitudes and Social Adaptation: A Person-Situation Interaction Approach, Oxford: Pergamon.

Kahle, L.R. and Homer, P.M. (1985) 'Physical attractiveness of the celebrity endorser: a social adaptation perspective', The Journal of Consumer Research, Vol. 11, No. 4, pp.954-961.

Kahle, L.R. and Timmer, S.G. (1983) 'A theory and a method for studying values', in L.R. Kahle (Ed.) Social Values and Social Change; Adaptation to Life in America, New York: Preager.

Kaikati, J.G. (1987) 'Celebrity advertising: a review and synthesis', International Journal of Advertising, Vol. 6, pp.93-105.

Kamen, J.M., Azhari, A.C. and Kragh, J.R. (1975) 'What a spokesman does for a sponsor', Journal of Advertising Research, Vol. 15, pp.17-24.

Kamins, M.A. (1990) 'An investigation into the "match-up" hypothesis in celebrity advertising: when beauty may be only skin deep', Journal of Advertising, Vol. 19, No. 1, pp.4-13.

Kamins, M.A. and Gupta, K. (1994) 'Congruence between spokesperson and product type: a matchup hypothesis perspective', Psychology and Marketing, Vol. 11, No. 6, pp.569-586.

Kamins, M.A., Brand, M.J., Hoeke, S.A. and Moe, J.C. (1989) 'Two-sided versus one-sided celebrity endorsements: the impact on advertising effectiveness and credibility', Journal of Advertising, Vol. 18, No. 2, pp.4-10. 
Kelly, H.H. and Michela, J.L. (1980) 'Attribution theory and research', Annual Review of Psychology, Vol. 31, pp.457-501.

Kelman, H.C. (1961) 'Processes of opinion change', Public Opinion Quarterly, Vol. 25, No. 1, pp. $57-78$.

Klebba, J.M. and Unger, L.S. (1982) 'The impact of negative and positive information on source credibility in a field setting', in R.P. Bogazzi and A.M. Tybout (Eds.) Advances in Consumer Research, Prove, UT: Association for Consumer Research, Vol. 10.

Larkin, M. (2002) 'Celebrity appeals for research dollars "intensifying" in USA', The Lancet, October, Vol. 1, p.339.

Louie, T.A. and Obermiller, C. (2002) 'Consumer responses to a firm's endorser (dis)association decisions', Journal of Advertising, Winter, Vol. 31, No. 4, pp.41-52.

McCracken, G. (1989) 'Who is the celebrity endorser? Cultural foundations of the endorsement process', The Journal of Consumer Research, Vol. 16, No. 3, pp.310-321.

McGuire, W. (1985) 'Attitudes and attitude change', in G. Lindzey and E. Aronson (Eds.) Handbook of Social Psychology, New York: Random House, Vol. 2, pp.233-346.

MacKenzie, S.B., Lutz, R.J. and Belch, G.E. (1986) 'The role of attitude toward the Ad as a mediator of advertising effectiveness: a test of competing explanations', Journal of Marketing Research, May, Vol. 23, pp.130-143.

Miller, G. and Basehart, J. (1969) 'Source trustworthiness, opinionated statements, and responses to persuasive communication', Speech Monographs, Vol. 36, No. 1, pp.1-7.

Miller, L.E. (2004) 'The changing nature of celebrity from entertainer to entrepreneur: Oprah Winfrey as tastemaker', Unpublished Master of Arts, Georgetown University, Washington, DC, USA

Mook, D.G. (1983) 'In defense of external validity', American Psychologist, Vol. 38, pp.379-387.

Nunnally, J.C. (1967) Psychometric Theory, New York: McGraw-Hill.

Nunnally, J.C. and Bernstein, I.H. (1994) Psychometric Theory, 3 ed., New York, NY: McGraw-Hill.

O'Mahony, S. and Meenaghan, T. (1998) 'The impact of celebrity endorsements on consumers', Irish Marketing Review, Vol. 10, No. 2, pp.15-24.

Ohanian, R. (1990) 'Construction and validation of a scale to measure celebrity endorsers' perceived expertise, trustworthiness, and attractiveness', Journal of Advertising, Vol. 19, No. 3, pp.39-52.

Ohanian, R. (1991) 'The impact of celebrity spokespersons' perceived image on consumer intention to purchase', Journal of Advertising Research, February-March, pp.46-54.

Petty, R., Cacioppo, J.T. and Schuman, D. (1983) 'Central and peripheral routes to advertising effectiveness: the moderating role of involvement', The Journal of Consumer Research, Vol. 10, No. 2, pp.135-146.

Ponce de Leon, C.L. (2002) In Self-Exposure: Human Interest Journalism and the Emergence of Celebrity in America, 1890-1940, Chapel Hill: University of North Carolina Press.

Pringle, H. and Binet, L. (2005) 'How marketers can use celebrities to sell more effectively', Journal of Consumer Behaviour, Vol. 4, No. 3, pp.201-214.

Robertson, T.S. and Rossiter, J.R. (1974) 'Children and commercial persuasion: an attribution theory analysis', Journal of Consumer Research, Vol. 1, No. 1, pp.13-20.

Shimp, T.A. (1997) Advertising, Promotion, and Supplemental Aspects of Integrated Marketing Communications, 4th ed., London: The Dryden Press.

Silvera, D.H. and Austad, B. (2004) 'Factors predicting the effectiveness of celebrity endorsement advertisements', European Journal of Marketing, Vol. 38, Nos. 11-12, pp.1509-1526.

Smith, R.E. and Hunt, S.D. (1978) 'Attributional processes and effects in promotional situations', The Journal of Consumer Research, Vol. 5, No. 3, pp.149-158. 
Stanley, T.L. (2004) 'Rocker Sammy Hagar turns "whim” into a solid business', Advertising Age, Vol. 75, No. 39, p.20.

Sternthal, B., Dholakia, R. and Leavitt, C. (1978) 'The persuasive effect of source credibility: tests of cognitive response', Journal of Consumer Research, Vol. 4, No. 4, pp.252-260.

Till, B.D. and Busler, M. (1998) 'Matching products with endorsers: attractiveness versus expertise', Journal of Consumer Marketing, Vol. 15, No. 6, pp.576-586.

Woodside, A. and Davenport, W. (1974) 'The effect of salesman similarity and expertise on consumer purchasing behavior', Journal of Marketing Research, May, Vol. 11, pp.198-202.

\section{Notes}

1 Erdogan presents an excellent review of celebrity endorsement literature.

2 Kelly and Michela (1980) write that attribution research can be divided into two streams: Those that look at the antecedents of attributions and that which looks at the consequences of attributions; the latter of which are referred to as 'attributional' research.

3 Correspondence bias has its roots in attribution theory and is one of the many diverse theories that constitute the field (Cronley et al., 1999).

4 For alternative explanations on how the source models work see e.g., (Kahle, 1984; Kahle and Timmer, 1983; Petty et al., 1983). 